\title{
Editorial
}

\section{Are You Being Served?}

\author{
MBoC: AT YOUR SERVICE
}

As the new editor-in-chief of Molecular Biology of the Cell (MBoC), I hope to advance the shared mission of the American Society for Cell Biology (ASCB) and its basic research journal. Toward that end, $M B O C$ will avoid some of the pernicious trends in scientific publishing that lead journals to seek status over substance. It will engage readers with new types of features and an enhanced online presence, and an expanded Editorial Board will continue to evaluate submissions according to clearly stated criteria designed to serve science.

$M B o C$ 's mission and that of the ASCB, which owns and manages the Journal, are entirely congruent. The ASCB was founded "to bring the varied facets of cell biology together. The Society's purpose is to promote and develop the field of cell biology" (ASCB, 2009). MBoC's mission "to enhance scientific communication among cell biologists" and "to serve all cell biologist authors" was articulated by David Botstein (Botstein, 1998), the first editor-in-chief after the journal Cell Regulation was rechristened MBoC. Sandy Schmid, MBoC's third editor-in-chief, aptly and succinctly pointed out: "It's our journal" (Schmid, 2005).

$M B o C$ was established by and is run by cell biologists for cell biologists. Its policies and practices were developed to serve scientists and advance the field of cell biology. Articles are thorough and complete. Substance is valued over trendiness. Scholarship and clarity are never compromised by arbitrary limitations on words, figures, or references.

$M B o C^{\prime}$ s editors share a commitment to serving cell biologists. Because they all are working scientists, the editors are able to distill reviewers' comments down to the essential points so authors don't get mired in trivia. Scientific standards are high, but the review process is fast and fair. Articles become accessible in the format of the originally submitted manuscript within approximately two weeks of acceptance, and access to the final, copyedited version becomes free just two months after publication.

\section{THE IMPACT FACTOR'S IMPACT}

What makes a journal good? In my view, a good journal moves a field forward by publishing reports on well-designed and -executed studies that advance knowledge and understanding and allows authors to communicate scientific advances clearly and efficiently to readers. That is what $M B O C$ will continue to do. But in so doing, our journal will be defying some ugly trends in scientific publishing.

Unfortunately, jockeying among science journals for position in the journal pecking order is at best tangential to, and more often at odds with, what is best for authors and readers. Although calculated in a dubious and nontransparent manner (Rossner et al., 2007), the impact factor is the metric most often used to rank journals.

The impact factor has had a negative impact on science publishing in two ways. First, when journals focus on optimizing their impact factor, they lose sight of, and are distracted from, what should be their only objective, which is to establish practices that are in the best interest of their authors and readers. Second, in giving importance to the impact factor, scientists and granting, hiring, and promotion committees are abdicating their responsibility to judge research articles based on their content. This unfortunate willingness to value the impact factor as a meaningful metric is particularly pervasive in Europe and Asia.

The current fixation on the impact factor fuels a feedback loop, wherein journals focus on attaining the highest impact factor and authors focus on publishing in journals with the highest impact factor. To attain higher impact factors, status-conscious journals are impelled to make highly subjective decisions on manuscript suitability. Quality and substance take a back seat to style and trendiness when editors try to weigh in their manuscript decisions how many citations an article is likely to receive.

As selectivity is ratcheted upward, arbitrary quotas on the number of articles accepted may be introduced. Irrespective of whether a journal is a nonprofit or for-profit and of whether manuscripts are handled by professional editors or working scientists, when a journal is accepting only $10-20 \%$ of submitted manuscripts, what results is a high level of subjectivity and a lack of transparency and consistency in how editorial decisions are made.

Other problems with science publishing are a reflection of practices and priorities that are not aligned with or motivated by a commitment to serving scientists and science. For example, the submission-reviewdecision process too often moves at a glacial pace. Reviewers sometimes write hypercritical and nonconstructive reviews and insist that authors write a different paper from the one they originally wrote. Authors are often made to respond to seemingly endless lists of reviewer's criticisms and as a result, spend months and months performing additional experiments that in the end don't affect the main conclusions of the work.

DOI: 10.1091/mbc.E09-09-0838

Address correspondence to: David G. Drubin (drubin@berkley.edu). 
Although most authors welcome constructive criticism, they also want to write their papers on their own terms. In the end, it is the author's paper, not the reviewer's paper.

Lastly, forcing authors to compromise thoroughness and scholarship because of severe space constraints on text, figures, and references is at odds with what should be the mission of every journal, which is to promote scientific communication and progress. Because of such constraints imposed by many journals, it is often necessary to relegate essential content to supplemental materials. Absurdly, the end result is the need to read two documents, the article and its supplement, to understand what the authors did. Who is being served by such practices?

\section{SERVING SCIENTISTS}

As I contemplate $M B o C^{\prime}$ s future, my thoughts are on how best to sustain and build on the legacy of my predecessors, who created a journal that for 20 years has succeeded in, and never waivered from, its mission of serving its authors and readers. Toward this end, the ASCB recently surveyed its membership to learn how effectively $M B O C$ serves cell biologists.

Eighty-four percent of the survey respondents agree or strongly agree that articles published in $M B o C$ are generally of high quality, and $85 \%$ agree or strongly agree that $M B o C$ articles in their field are generally worth reading. (Complete numerical survey results are available at www.ascb.org/files/Member_Survey_MBoC_ Results.pdf.) Credit for this laudable state of affairs goes to the skillful and highly principled stewardship of Cell Regulation's founding editor, Erkki Ruoslahti; to $M B o C^{\prime}$ 's three past editors-in-chief: David Botstein, Keith Yamamoto, and Sandra Schmid; to $M B C^{\prime}$ 's talented and highly dedicated staff: Joan Goldberg, Mark Leader, Eric Baker, and Ricardo Fernandez; and to its dedicated board of volunteer editors.

Although most ASCB members value $M B O C$ highly, the survey identified opportunities for improvement. For example, authors favor introduction of features that will help draw attention to $M B o C$ articles. Also favored are improvements in $M B o C^{\prime}$ s electronic presence and the publication of engaging "front matter" articles.

Guided by this feedback, we are introducing some new features to the Journal. In making these changes, we are continuing $M B O C^{\prime}$ s tradition of making innovations that enhance its ability to serve cell biologists. Under David Botstein, $M B \circ C$ became a leader in accommodation of large data sets and video data. Under Sandy Schmid, the Journal became entirely electronic, liberating $M B O C$ from the constraints of a print journal-we can publish as many worthy articles as we receive, and the results and methods can be documented in full within the body of the article. Also, to expedite the review process, $M B o C$ now invites authors to submit for consideration with their manuscripts, rejection letters and accompanying reviews received from other journals. This policy represents a clear statement that $M B C^{\prime}$ 's priority is to serve authors and science and to promote progress in cell biology research.

\section{HOW WE ARE CHANGING}

To advance $M B o C^{\prime}$ 's mission, we will be adding new members to the Editorial Board, adding engaging articles in new formats, and updating the Journal's Web presence.

I am happy to announce that James Nelson will join our team of Editors, together with outgoing Editor-in-Chief Sandy Schmid, who has graciously agreed to serve as an Editor. Jean Schwarzbauer and Tom Pollard will continue to serve as editors. This team will provide $M B o C$ with continuity, leadership, and guidance.

In addition, we are making strategic Editorial Board appointments to achieve specific goals. New Associate Editors are being appointed for two purposes. First, since ASCB members are located in 65 countries in addition to the United States and since outstanding cell biology research is being done all over the world, international representation on the board is being sharply increased. Second, we are adding or enhancing expertise in areas of cell biology that stand at the intersection between disciplines, including mathematical modeling, high content screening, technology development, disease models, metabolomics, systems biology, and bioengineering.

In this issue you will notice new "front matter" features. Retrospectives are reflections of an historical, educational, and philosophical nature, on past scientific advances. The first set of Retrospectives will highlight some of the most highly cited $M B O C$ articles, with an article by David Botstein appearing in this issue. One thing we are working toward is better integration between $M B O C$ and the ASCB. In this spirit, you will find in this issue ASCB Award Essays by Peter Walter (EB Wilson Award), Ron Vale (Porter Lecture), Janet Rossant (Senior WICB Award), and Yukiko Yamashita (Junior WICB Award), all award recipients at the 2009 ASCB meeting. In the future, you can look forward to engaging front matter content on a regular basis. I am happy to announce that Doug Kellogg has agreed to become the Features Editor responsible for soliciting front matter articles.

We are looking forward to the launch of a redesigned Web site in 2010, with features that are more engaging and interactive. In the past, journal covers provided a way to highlight articles. However, like music album covers, journal covers have lost their importance as content shifts from print to electronic. How can we draw attention to our journal and our articles and how can we highlight especially noteworthy articles? We will endeavor to increase $M B o C^{\prime}$ 's electronic presence, and in so doing, to better highlight $M B o C^{\prime} \mathrm{s}$ content. We will use electronic media to achieve integration between $M B o C$ and the ASCB and to make sure that $\mathrm{MBoC}$ articles are brought to the attention of each of the ASCB's members.

Finally, because $M B O C$ publishes many fine articles, we will be highlighting more of them in the $A S C B$ Newsletter and in the tables of contents. "InCytes from $M B o C$," which has appeared in each issue of the $A S C B$ 
Newsletter, will be replaced with "Highlights from $M B \circ C$." Highlights from $M B o C$ will include brief summaries of all articles nominated for highlighting by the Editorial Board.

\section{SETTING THE BAR FOR MANUSCRIPT ACCEPTANCE}

$M B o C$ can only fulfill its mission to "develop the field of cell biology" if standards for manuscript acceptance are high. And, cell biologists will only be served if standards are set and applied in a principled, consistent, and completely transparent manner. Our general standards for manuscript acceptance have previously been formalized:

$M B o C$ does not, in general, publish articles that are narrow in scope and better suited to more specialized journals, merely confirmatory or preliminary reports of partially completed or incompletely documented research, findings of as yet uncertain significance, or reports that simply document well-known processes in organisms or cell types not previously studied.

To make our manuscript review criteria more explicit and consistently applied, the Editorial Board will work to develop specific guidelines for rigor and completeness. That way, authors will have a clear idea of what is expected of them and how the Editorial Board will assess the quality of manuscripts.

Finally, more rigorous standards for manuscript clarity and conciseness will be applied. Although conversion of $M B O C$ to an all-electronic journal allows us to remain free from arbitrary limits on the number of papers accepted and on manuscript length, our articles will be read more widely and thoroughly if the writing is clear and succinct. In the words of Antoine de Saint-Exupery, "Perfection is achieved, not when there is nothing more to add, but when there is nothing left to take away."

Are you being served?

David G. Drubin Editor-in-Chief

\section{REFERENCES}

ASCB. (2009). About the ASCB. http://www.ascb.org/index.php?option=com_content\&view=article\&id=16\&Itemid=18 (accessed 25 September 2009).

Botstein, D. (1998). Editorial. Mol. Biol. Cell 9(7), i.

Rossner, M., Van Epps, H., and Hill, E. (2007). Show me the data. J. Cell Biol. 179, 1091-1092.

Schmid, S. L. (2005). Molecular Biology of the Cell: it's our journal. Mol. Biol. Cell 16(1), i-ii. 